\title{
Examination of serum pregnancy-associated plasma protein A clinical value in acute coronary syndrome prediction and monitoring
}

\author{
Rafał Nikodem Wlazet'1, Jacek Rysz², Marek Paradowski'
}

1Department of Laboratory Medicine and Clinical Biochemistry, Medical University of Lodz, Poland

2Department of Nephrology, Hypertension and Family Medicine, Medical University of Lodz, Poland

Submitted: 7 July 2011

Accepted: 20 December 2011

Arch Med Sci 2013; 9, 1: 14-20

DOI: 10.5114/aoms.2013.33343

Copyright $\odot 2013$ Termedia \& Banach

\section{Abstract}

Introduction: Chronic vascular inflammatory process promotes and intensifies all atherogenic events. The aim of this research was to estimate the clinical value of pregnancy-associated plasma protein A (PAPP-A) measurement associated with plaque destabilization and rupture in prediction and monitoring of acute coronary syndromes (ACS) as well as to assess the predictive value of this biomarker in comparison to traditional myocardial infarction (MI) risk markers.

Material and methods: The study included 119 patients in 2 investigated groups and one control group. PAPP-A assay was performed using manual ELISA kit, DRG. All other parameters were determined using automatic analyzers: Olympus and Dade Behring.

Results: A statistically significant difference between PAPP-A concentration median value was found in the investigated group $M I$ individuals' serum and control group individuals' serum ( $11.42 \mathrm{ng} / \mathrm{ml}$ and $7.22 \mathrm{ng} / \mathrm{ml}$ respectively, $p=0.003$ ). PAPP-A assay had the highest specificity (83.3\%) and sensitivity (53.8\%), and therefore the highest clinical value. In patients with clinically and laboratory confirmed MI we proved that PAPP-A serum level is a clinically useful biomarker in ACS prediction, better than C-reactive protein (hsCRP) and fibrinogen (FBG) level.

Conclusions: The highest diagnostic efficiency for ACS prediction was proved for simultaneous panel assays consisting of 2-3 parameters (PAPP-A - hsCRP, PAPP-A - FBG, PAPP-A - hsCRP - FBG), while PAPP-A itself does not show characteristics necessary for it to be used as a biomarker for $\mathrm{MI}$ dynamic monitoring. It is possible that prothrombotic component is mainly responsible for repeated major adverse cardiac events, more than inflammatory process.

Key words: pregnancy-associated plasma protein A, acute coronary syndrome, myocardial infarction prediction, biomarker.

\section{Introduction}

It is commonly known that in acute coronary syndrome, prevention is as important as treatment. That is why along with classical risk factors, special notice should be taken of those that can be measured, hence becoming risk indicators [1]. The widely used preventive panel includes serum lipid profile, glucose and fibrinogen level as well as more and more often C-reactive protein indicated by the high-sensitivity method (hSCRP).

\section{Corresponding author:}

Rafał Nikodem Wlazeł PhD

Department

of Laboratory Medicine and Clinical Biochemistry Medical University of Lodz 113 Zeromskiego Str. 90-549 Lodz, Poland Phone: +48 426393655 E-mail: rnw@wp.pl 
Recent publications contain many studies suggesting the necessity of adding to the panel some biomarkers that define the degree of ACS risk [2]. Among the biomarkers, particularly important seem to be those whose level in the bloodstream precedes the cardiac event, and whose increase in concentration is related directly to the occurrence of those incidents or even determines them $[3,4]$. This group includes inflammatory state biomarkers, commonly known as inflammatory proteins responsible for plaque destabilisation. Our particular attention was drawn to pregnancy-associated plasma protein A (PAPP-A) (pappalysin-1, EC 3.4.24.79). It is a zinc-binding metalloproteinase, whose known substrates present in humans are insulin-like growth factor binding proteins 4 and 5 [5]. For a few years it has been used in routine prenatal diagnostics of Down's syndrome. It is physiologically synthesised by the syncytiotrophoblast and released to the bloodstream of a pregnant woman in concentrations increasing with the advancement of the pregnancy. However, in the case of Down's syndrome, the concentration of PAPP-A in serum stays at significantly low levels during the first trimester. A low level of this protein is also observed in men and non-pregnant women [6]. Pregnancyassociated plasma protein $A$ is synthesized in tissues related to reproduction (ovaries, endometrium, myometrium) and also in kidneys, colon and bone marrow cells $[7,8]$. Elevated levels of PAPP-A appear in blood in relation to plaque destabilisation [9]. It is assumed, however, that in this situation the protein is produced within the plaque and shows different structure, which can cause potential methodology problems [10]. In a physiological environment, PAPP-A circulates in the blood as a heterotetramer composed of two peptides of the enzyme (mass 200-250 kDa), staying in a covalent bond with two molecules of its endogenous inhibitor pro-MBP (eosinophil major basic protein, mass $50-90 \mathrm{kDa}$ ). The PAPP-A coming from destabilised plaque is a homodimer, which makes it potentially difficult to track in immunochemical tests [11]. The tests are meant to detect biologically non-active molecules (associated with pro-MBP). Bayes-Genis et al. [12] were among the first to conduct immunochemical research that showed the presence of a significant amount of this very form of PAPP-A in ruptured plaque and a small amount of it in stable plaque. So far indirect release of PAPPA from the plaque has not been proved. BayesGenis et al. as well as Conover et al. [13] attribute the production of this protein to the plaque smooth muscles cells, whereas Sangiorni et al. [14] suggest that monocytes/macrophages produce and release PAPP-A. Nevertheless, the authors agree that PAPP$A$ is associated with plaque destabilisation. This allows intensive research to be conducted in order to include this protein in the group of plaque destabilisation biomarkers useful in ACS prediction [15-18]. The latest publications suggest that a full diagnostic and preventive strategy for cardiovascular disease and its consequences should be based on indication of a few versatile sets of biomarkers different in terms of the disease pathophysiology $[19,20]$. Plaque destabilisation markers could be a good supplement to the existing diagnostic panel as they carry some independent predictive information.

The aim of the study was to estimate the clinical value of PAPP-A concentration in ACS prediction and monitoring and to assess the predictive value of the biomarker in question in comparison to existing myocardial infarction (MI) risk markers for ACS prediction.

\section{Material and methods}

The study included 119 patients in two investigated groups and one control group. The first investigated group consisted of patients suffering from their first clinically confirmed MI with elevated levels of cTnl. From the first pain in the chest or its equivalent until admission no more than $3 \mathrm{~h}$ passed. It enabled us to assume that all the changes in the level of investigated biochemical parameters were not directly caused by the myocardial infarction but they reflected the state in coronary vessels before the incident. There was no heparin administration before colleting blood. The treatment we used was percutaneous coronary intervention $(\mathrm{PCl})$. The second investigated group included patients with an earlier cardiovascular event in the history who had undergone primary vascular angioplasty with stent implantation and in whom a major adverse cardiac event (MACE) had occurred within 15 months. As MACE we defined another $\mathrm{PCl}$, coronary artery bypass graft or secondary hospitalisation for cardiac reasons. The patients were given statins, acetylsalicylic acid (ASA), thienopyridine derivative and, where possible, $\beta$-blocker and angiotensin-converting enzyme inhibitor as preventive measures. The patients were included in the research after completion of the treatment. The control group (C) consisted of randomly chosen generally healthy individuals without cardiovascular episodes in their history or previous cardiac events, with no manifestation of clinical chronic disorders or no awareness of such. Based on a detailed interview with the patients, the laboratory indication results determined whether the individual was qualified for the research (results within reference value) or excluded from it (pathological results). Detailed group characteristics are presented in Table I.

The material used was blood samples taken from the basilic vein and put into Sarstedt tubes (aspi- 
Table I. Group characteristics including frequency of risk markers

\begin{tabular}{|lccc|}
\hline Parameter & MI $(n=40)$ & MACE $(n=41)$ & C $(n=38)$ \\
\hline Age [years] & $30-78$ & $43-80$ & $40-67$ \\
\hline Smoking, $n(\%)$ & $30(75)$ & $25(61)$ & $6(15.8)$ \\
\hline Diabetes & $7(17.5)$ & $6(14.6)$ & $0(0)$ \\
\hline BMI $>25\left[\mathrm{~kg} / \mathrm{m}^{2}\right], n(\%)$ & $26(65)$ & $21(51.2)$ & $4(10.5)$ \\
\hline HDL-cholesterol: $\mathrm{M} \leq 40 \mathrm{mg} / \mathrm{dl}, \mathrm{F} \leq 50 \mathrm{mg} / \mathrm{dl}$ & $10(25)$ & $11(26.8)$ & $3(7.9)$ \\
\hline Triglicerydes $\geq 150 \mathrm{mg} / \mathrm{dl}$ & $20(50)$ & $25(61)$ & $4(10.5)$ \\
\hline hsCRP $>3 \mathrm{mg} / \mathrm{l}$ & $9(22.5)$ & $9(22)$ & $8(21)$ \\
\hline
\end{tabular}

Table II. Detailed statistical analysis of results obtained in investigated groups in comparison with the control group

\begin{tabular}{|lcccc|}
\hline Parameter & Group & Median & 25th-75th Percentile & $\begin{array}{c}\text { Value of } p \\
\text { (in comparison with C group) }\end{array}$ \\
\hline hsCRP [mg/l] & MI & 1.65 & $0.80-4.80$ & 0.052 \\
\cline { 2 - 5 } & MACE & 1.60 & $0.80-2.70$ & - \\
\cline { 2 - 5 } & C & 1.00 & $0.60-2.40$ & 0.0085 \\
\hline FBG [g/dl] & MI & 402 & $283-500$ & - \\
\cline { 2 - 5 } & MACE & 465 & $360-594$ & - \\
\hline PAPP-A [ng/ml] & MI & 368 & $263-379$ & 0.0026 \\
\cline { 2 - 5 } & MACE & 4.87 & $7.03-18.33$ & - \\
\cline { 2 - 5 } & C & 8.30 & $3.31-7.38$ & - \\
\hline MI & MACE & 4.73 & $4.79-8.81$ & 0.5 \\
\cline { 2 - 5 } & C & 5.87 & $4.05-5.92$ & - \\
\hline
\end{tabular}

ration vacuum principle). The following were measured indirectly after taking: in plasma - fibrinogen concentration; in serum - the concentration of HDL cholesterol, triglycerides, high-sensitivity C-reactive protein (hsCRP), cardiac troponin I (cTnl) and PAPP-A (Tables I, II). In order to examine the concentration dynamics of the biomarker in question during the course of the spreading coronary attack in the group MI individuals, the CTnl and PAPP-A levels were measured at five points: on admission (no heparin administration before sampling), and then 6, 12, 24 and $48 \mathrm{~h}$ following admission.

Biochemical parameter concentrations were measured with an AU 640 biochemical analyser and Siemens reagents. A Sysmex analyser and Siemens reagents were used to measure fibrinogen concentration in serum. Cardiac troponin I (cTnl) concentration was measured by enzyme-linked fluorescent assay (ELFA) technology with a Vidas analyser and Biomerieux reagents. The PAPP-A was measured by manual enzyme-linked immunosorbent assay (ELISA) method with PAPP-A US (ultra sensitive) kits manufactured by DRG Germany designed especially to detect low concentrations of enzyme circulating in serum in association with plaque destabilisation.

The research was conducted with the consent of the Bioethics Commission at the Medical University in Lodz on the basis of the Bioethics Commission Resolution concerning medical experiment project number RNN/355/KB dated 24 October 2006.

\section{Statistical analysis}

The consistency of results distribution for individual parameters with normal distribution was specified with the Wilk-Shapiro test. To analyse the significance of differences between individual groups a non-parametric Mann-Whitney $U$ test was used. To analyse the significance of differences in the case of distribution consistent with normal distribution the $T$ test for independent samples was used. The correlation between chosen parameters was investigated by non-parametric Spearman test.

The interdependence between sensitivity and specificity of the assay and hence the clinical value of the laboratory test was presented graphical- 
ly and numerically for all cut-off values in ROC curves. The relative area under the curve (AUC) was defined.

\section{Results}

The study found a statistically significant difference between PAPP-A concentration median value in the investigated group of MI individuals' serum and control group individuals $(11.42 \mathrm{ng} / \mathrm{ml}$ and $7.22 \mathrm{ng} / \mathrm{ml}$ respectively, $p=0.003$ ). That corresponds to recent publications on the subject and can confirm the thesis about releasing larger amounts of the biomarker in question to the bloodstream in association with the plaque destabilisation process which can indirectly precede coronary disease aggravation such as cardiac arrest.

The statistical analysis of the results showed that PAPP-A concentration measurement for coronary attack prediction in group $\mathrm{MI}$ had the highest diagnostic specificity and sensitivity $(83.3 \%$ and $53.8 \%$; cut-off $=9.4 \mathrm{ng} / \mathrm{ml}$ ), which made it the most clinically useful (Table III). Relative AUC for this biomarker was 0.720 and was greater than the AUC for the existing risk indicators hsCRP (AUC $=0.631)$ and fibrinogen (FBG) (AUC = 0.680). What is more, PAPP-A measurement together with existing mark- ers hsCRP and FBG (AUC $=0.751$ and $\mathrm{AUC}=0.795$, respectively) raised the diagnostic value of their measurement for ACS prediction. On the other hand, FBG and hsCRP measurement simultaneously with PAPP-A increased the PAPP-A predictive value normally measured on its own. Sensitivity and specificity of this biomarker triad were $80.0 \%$ and $64.7 \%$, respectively (AUC $=0.756$ ), whereas the positive and negative prediction values were $70 \%$ and $76 \%$, respectively (Figure 1 ). The PAPP-A concentration value did not show a significant difference at individual measurement points in the MI group compared to cTnl concentration medians for myocardium necrosis (Figure 2).

The PAPP-A and FBG concentration medians values were different in the investigated group and control group and were respectively $11.42 \mathrm{ng} / \mathrm{ml}$ and $7.22 \mathrm{ng} / \mathrm{ml}(p=0.003)$ and $401.6 \mathrm{mg} / \mathrm{dl}$ and $314.5 \mathrm{mg} / \mathrm{dl}(p=0.009$ ) (Table II). It is worth noting that no statistically significant differences were found between those groups in median values of hsCRP and cholesterol $(p>0.05)$.

In the MACE group the FBG concentration value was the highest $(479 \mathrm{mg} / \mathrm{dl})$ in comparison to low average concentrations of the other analysed parameters $(\mathrm{Ml}=420 \mathrm{mg} / \mathrm{dl}, \mathrm{C}=332 \mathrm{mg} / \mathrm{dl}$; $p=0.008$ and $p=0.00002$ respectively).

Table III. Statistical analysis of clinical value of laboratory tests in MI prediction

\begin{tabular}{|lcccc|}
\hline Biomarker & AUC & Cut-off & Sensitivity [\%] & Specificity [\%] \\
\hline hsCRP & 0.63 & $4.1 \mathrm{mg} / /$ & 28.9 & 97.2 \\
\hline FBG & 0.68 & $379 \mathrm{~g} / \mathrm{dl}$ & 60.5 & 76.5 \\
\hline PAPP-A & 0.72 & $9.4 \mathrm{ng} / \mathrm{ml}$ & 53.8 & 83.3 \\
\hline FBG + hsCRP + PAPP-A & 0.76 & - & 80.0 & 64.7 \\
\hline
\end{tabular}

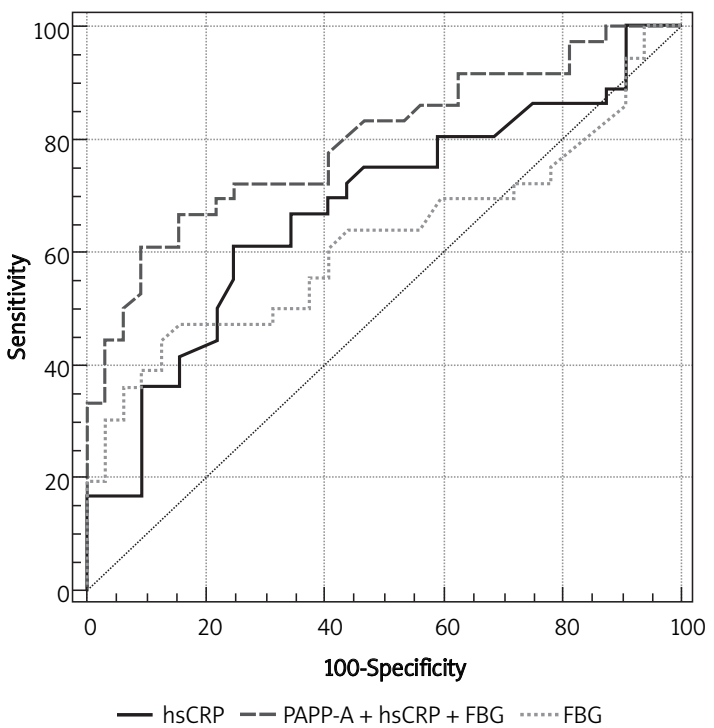

Figure 1. Clinical value of biomarker measurement in $\mathrm{Ml}$ group in comparison with the control group
A
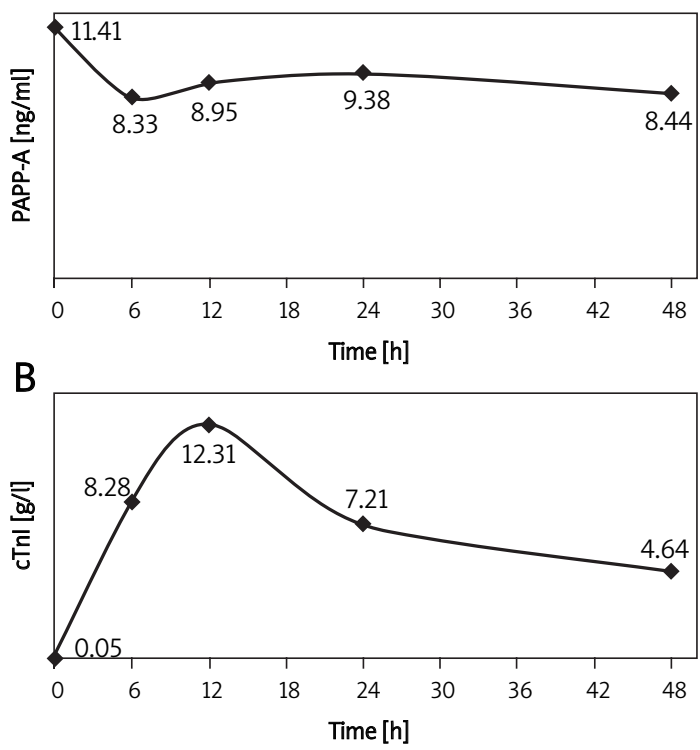

Figure 2. PAPP-A (A) in comparison with $\mathrm{CTnl}(\mathrm{B})$ concentration dynamics during the course of spreading $\mathrm{MI}$ 


\section{Discussion}

Plaque destabilization and rupture are direct and the most common cause of ACS. The chronic vascular inflammatory process promotes and intensifies all atherogenic events; therefore for a few years research has been undertaken to discover inflammation markers that could improve laboratory predictive assessment of ACS [21-26].

Bayes-Gensis et al. found the presence of PAPP-A in unstable plaque in patients who died suddenly during the course of ACS. They described the phenomenon of increased PAPP-A concentration in patients suffering from unstable angina and ACS [27]. According to another study, PAPP-A concentration measurement seems to be useful for the detection of unstable vascular disease even in patients who do not show increased concentrations of myocardial necrosis biomarkers [28]. In both the above studies, the correlation of PAPP-A and CTnl levels was weak, which disqualifies this enzyme as a potential myocardial necrosis marker. PAPP-A concentration in the blood of patients with ACS starts increasing not earlier than during the $2^{\text {nd }} \mathrm{h}$ and not later than after the thirtieth hour following the occurrence of the first symptoms. Only in $2 / 3$ of the patients does the PAPP-A concentration remain at the same level. What is more, the research showed that PAPP-A is found only in ruptured plaque and is not observed in stable plaque. Our research did not confirm the phenomenon of PAPP-A concentration increase in serum during the $1^{\text {st }} h$ of the attack.

In some other research which included $547 \mathrm{pa}-$ tients with angiographically proved ACS and an additional group of 644 patients with acute chest pain, PAPP-A concentrations were an important risk marker both in the group with increased cardiac troponin I concentration and in the group with its normal level [29]. It was also observed that PAPP-A concentration does not correlate either with lipid profile parameters or with any other inflammatory markers. It does not clearly show that PAPP-A is an inflammatory mediator. Additionally, it was proved that PAPP-A sensitively reflects changes in kidney function, especially in patients who undergo dialysis. The PAPP-A shows a positive correlation with serum creatinine concentration, which disqualifies its prognostic value for ACS risk in patients with kidney dysfunction [30]. The clinical value of PAPP-A measurement as a marker for cardiovascular events in patients with hyperlipidaemia who showed no clinical symptoms of ACS risk was examined. A correlation of the enzyme concentration increase with carotid plaque echogenicity was also observed [31]. Still, PAPP-A concentration did not depend on statin treatment [32]. The research also indicated that PAPP-A concentration increase does not necessarily represent ACS cases. It can also reflect earlier stages of atheromatosis changes even before there are any clinical atheromatosis symptoms [33-36]. Recent publications also indicated that PAPP-A concentration within the range of the highest percentile in patients admitted to A\&E with stenocardial pain preceding ACS was associated with a high risk of late complications leading to death within the following 12 months after a coronary attack $[37,38]$. On the other hand, Iversen [39] described PAPP-A concentration dynamics in patients with ACS symptoms without ST-segment rising, indicating this protein as a marker of ischaemia in patients with low and high risk of cardiovascular disease aggravation. The PAPP-A concentration dynamics observed in MI patients based on our research strictly correspond to those results. This fact leads to the conclusion that PAPP-A level in serum does not change significantly during myocardial infarction. This reinforces previous observations concerning this biomarker increase in association with plaque destabilisation. The latter being a process occurring before myocardial infarction confirms the legitimacy of using PAPP-A measurement as a prediction marker.

The same author pointed out that elevation of PAPP-A in patients with acute coronary syndromes may be caused by heparin-induced release of PAPP-A from the arterial wall and not due to excretion from vulnerable plaques [40]. In our research there was no heparin treatment before blood collection.

In conclusion, thus we can conclude that PAPP-A is not a clinically useful biomarker in monitoring the course of coronary attack. What is more, PAPP-A concentration in serum measurement as a useful marker for ACS prediction seems to be better than CRP and FBG concentration evaluation. The highest diagnostic efficiency for ACS prediction was proved for simultaneous panel assays consisting of 2-3 parameters (PAPP-A - hsCRP, PAPP-A - FBG, PAPP-A - hsCRP - FBG).

The results of the study also indicated that a high FBG level together with a relatively low CRP level in serum of patients who had suffered from a coronary attack may lead to the conclusion that it is the prothrombotic component in the form of increased "thrombotic readiness" that is mainly responsible for repeated MACE. However, in literature the authors consider other pathological processes that may play important role in risk assessment after acute myocardial infarction [41, 42].

A relatively small number of patients included in the research might have been a certain limitation influencing the statistical results. It is also not clear whether single PAPP-A concentration measurement is sufficient for the risk stratification. The directives of the American Heart Association and Centers for Control and Prevention concerning inflammatory markers recommend measuring CRP twice with 
a 2-to-3-week interval during full metabolic efficiency (general health) [43]. Additionally, so far it has not been possible to state how long before the cardiac event PAPP-A level rises [44], which further limits the cohesion of interpretation of measurement of the marker in question.

\section{Acknowledgments}

This research was supported by grant from the Medical University of Lodz (502-03/5-020-01/50254-064). The research was conducted using ELISA kits manufactured by DRG Germany. We are thankful for release of the PAPP-A kits for free.

\section{References}

1. Lai HM, Aronow WS, Mercando AD, et al. Risk factor reduction in progression of angiographic coronary artery disease. Arch Med Sci 2012; 8: 444-8.

2. Apple FS, Wu AHB, Mair J, et al. Future biomarkers for detection of ischemia and risk stratification in acute coronary syndrome. Clin Chem 2005; 51: 810-24.

3. Panteghini M. Biochemical markers of cardiac diseases. Jugoslov Med Biohem 2004; 23: 201-11.

4. Vasan RS. Biomarkers of cardiovascular disease: molecular basis and practical consideration. Circulation 2006; 113: 2335-62.

5. Lawrence JB, Oxving C, Overgaard MT, et al. The insulinlike growth factor (IGF)-dependent IGF binding protein-4 protease secreted by human fibroblast is pregnancyassociateg plasma protein-A. Proc Natl Acad Sci USA 1999; 96: 3149-53.

6. Qin QP, Laitinen P, Majamaa-Voltti K, et al. Release patterns of pregnancy-associated plasma protein-A (PAPP-A) in patients with acute coronary syndromem. Scand Cardiovasc J 2002; 36: 358-61.

7. Qiu QP, Kokkala, Lund L, et al. Molecular distinction of circulating pregnancy-associated plasma protein $\mathrm{A}$ in myocardial infarction and pregnancy. Clin Chem 2005; 51: 75-83.

8. Qiu QP, Wittfooth S, Pettersson K. Measurment and clinical significance of circulating PAPP-A in ACS patients. Clin Chim Acta 2007; 380: 59-67.

9. Consuegra-Sanchez L, Frederics S, Kaski JC. Pregnancyassociated plasma protein-A (PAPP-A) and cardiovascular risk. Atherosclerosis 2009; 203: 346-52.

10. Khosravi J, Diamandi A, Kriszna RG, et al. Pregnancy associated plasma protein-A: ultrasensitive immunoassay and determination in coronary heart disease. Clin Biochem 2002; 35: 531-8.

11. Oxvig C, Sand O, Kristensen T, et al. Circulating human pregnancy-associated plasma protein-A is disulfidebridged to the proform of eosinophil major basic protein. J Biol Chem 1993; 268: 12243-6.

12. Bayes-Gensis A, Conover CA, Overgaard MT, et al. Pregnancy-associated plasma protein A predicts outcome in patients with acute coronary syndromes. N Engl J Med 2001; 345: 1022-39.

13. Bayes-Genis A, Conover CA, Overgaard MT, et al. Pregnancy associated plasma protein $A$ as a marker of acute coronary syndromes. N Eng J Med 2001; 51: 810-24.

14. Sangiorni G, Maurielo A, Bonanno E, et al. Pregnancyassociated plasma protein $A$ is markedly expressed by monocyte-macrophage celles in vulnerable and ruptured carotid atherosclerotic plaques: a link between inflammation and cerebrovascular events. J Am Coll Cardiol 2006; 47: 2201-11.

15. Elesber AA, Lerman A, Denktas AE, et al. PAPP-A and risk stratification of patients presenting with chest pain in the emergency department. Int J Cardiol 2006; 117: 365-9.

16. Laeterza OF, Cameron AJ, Chappell D, et al. Evaluation of PAPP-A as a prognostic indicator in acute coronary syndrome patients. Clin Chim Acta 2004; 348: 163-9.

17. Thorn EM, Khan IA. PAPP-A: an emerging cardiac biomarker. Int J Cardiol 2007; 117: 370-2.

18. Kaski JC, Holt DW. PAPP-A and cardiovascular risk. Eur Heart J 2006; 27: 1637-9.

19. Wu AHB. Markers of early detection of cardiac diseases. Scand J Clin Lab Invest 2005; 65 (Suppl 240): 112-21.

20. Apple FS, Pearce EA, Chung A, et al. Multiple biomarker use for detection of adverse events in patients presenting with symptoms suggestive of acute coronary syndrome. Clin Chem 2007; 53: 874-81.

21. Barylski M, Małyszko J, Rysz J, et al. Lipids, blood pressure, kidney - what was new in 2011? Arch Med Sci 2011; 7: 1055-66.

22. Otocka-Kmiecik A, Mikhailidis DP, Nicholls SJ, et al. Dysfunctional HDL: a novel import ant diagnostic and therapeutic target in cardiovascular disease? Prog Lipid Res 2012; 51: 314-24.

23. Rizzo M, Rini GB. Ezetimibe, cardiovascular risk and atherogenic dyslipidaemia. Arch Med Sci 2011; 7: 5-7.

24. Banach M, Markuszewski L, Zasłonka J, et al. The role of inflammation in the pathogenesis of atherosclerosis. Przegl Epidemiol 2004; 58: 663-70.

25. Libby P, Ridker PM. Inflammation at atherosclerosis. Circulation 2002; 105: 1135-43.

26. Veselka J, Hájek P, Malý M, et al. Predictors of coronary intervention-related myocardial infarction in stable angina patients pre-treated with statins. Arch Med Sci 2011; 7: 67-72.

27. Byes-Gensis A, Conover CA, Overgaard MT, et al. Pregnancy-associated plasma protein A predicts outcome in patients with acute coronary syndromes. N Engl J Med 2001; 345: 1022-39.

28. Lund J, Qin QP, Ilva T, et al. Circulating pregnancyassociated plasma protein A predicts outcome in patients with acute coronary syndrome but no troponin I elevation. Circulation 2003; 108: 1924-6.

29. Dominiguez-Rodriguez P, Abreu-Gonzales P, GarciaGonzalez M, et al. Circulating pregnancy associated plasma protein $\mathrm{A}$ is not an early marker of acute myocardial infarction. Clin Biochem 2005; 38: 180-2.

30. Fialova L, Kalousova M, Soukupova J, et al. Relationship of pregnancy-associated protein A to renal function anddialysis madalities. Kidney Blood Press Res 2004; 27 : 88-9.

31. Beaudeux JL, Burc L, Imbert-Bismut F, et al. Serum plasmapregnancy-associated plasma protein A. A potential marker ofechogenic carotid atherosclerotic plaques in asymptomatic hyperlipidemic subjects at high cardiovascular risk. Arterioscler Thromb Vasc Biol 2003; 23: E7-10.

32. Stulc T, Malbohan I, Malik J, et al. Increased levels of pregnancy associated plasmaprotein-A in patients with hipercholesterolemia: the effect of atorvastatin treatment. Am Heart J 2003; 146: E21.

33. Bayes-Genis A, Schwartz RS, Lewis DA, et al. Insuline-like growth factor binding protein-4 protease produced by smooth muscle cells increases in the coronary artery 
after angioplasty. Arterioscler Thromb Vasc Biol 2001; 21: 335-41.

34. Mueller T, Dieplinger B, Poelz W, et al. Increased pregnancy-associateg plasma protein-A as a marker for peripherial atherosclerosis: results from the linz peripheral arterial disease study. Clin Chem 2006; 52: 1096-103.

35. Crea F, Andreotti F. Pregnancy associated plasma protein-A and coronary atherosclerosis: marker, friend, or foe? Eur Heart J 2005; 26: 2075-6.

36. Aso Y, Okumura K, Wakabayashi S, et al. Elevated pregnancy-assiciated plasma protein-A in sera from type 2 diabetic patients with hypercholesterolemia: associations with carotid atherosclerosis and toe-brachial index. J Clin Endocrinol Metab 2004; 89: 5713-7.

37. Kavsak PA, Wang $X$, Henderson M, et al. PAPP-A as a marker of increased long-term risk in patients with chest pain. Clin Biochem 2009; 42: 1012-8.

38. Lund J, Qiin QP, Ilva T, et al. Pregnancy associated plasma protein A: a biomarker in acute ST-elevation myocardial infarction (STEMI). Ann Med 2006; 38: 221-8.

39. Iversen KK, Teisner AS, Teisner B, et al. Pregnancy associated plasma protein A, a potential marker for vulnerable plaque in patients with non-ST-segment elevation acute coronary syndrome. Clin Biochem 2009; 42: 828-34.

40. Iversen K, Teisner A, Dalager S, et al. Pregnancy associated plasma protein-A (PAPP-A) is not a marker of the vulnerable atherosclerotic plaque. Clin Biochem 2011; 44: 312-8.

41. Szadkowska I, Pawlicki L, Kowalski J, et al. Left ventricular dysfunction and NT-proBNP levels in patients with onevessel disease after first ST-elevation myocardial infarction treated with primary coronary angioplasty. Kardiol Pol 2009; 67: 1201-6.

42. Kaminski KA, Kozieradzka A, Bonda T, et al. Percutaneous coronary interventions affect concentrations of interleukin 6 and its soluble receptors in coronary sinus blood in patients with stable angina. Angiology 2009; 60: 322-8.

43. Pearsons TA, Mensah GA, Alexander RW, et al. Markers of inflammation and cardiovascular disease: application to clinical and public health practice: a statement for healthcare professionals from the Centers for Disease Control and Prevention and the American Heart As sociation. Circulation 2003; 107: 499-511.

44. Andreotti F, Rio T, Conti E. Role of PAPP-A in atherothrombosis: messages to take home. Atherosclerosis 2009; 203: 353-4. 